\title{
A review of pulmonary function in Parkinson's disease
}

This article was published in the following Dove Press journal: Journal of Parkinsonism and Restless Legs Syndrome

\author{
Ailish O'Callaghan' \\ Richard Walker ${ }^{2,3}$ \\ 'Department of Medicine, North \\ Cumbria University Hospitals NHS \\ Trust, Cumbria, ${ }^{2}$ Department of \\ Medicine, Northumbria Health Care \\ NHS Foundation Trust, Northumbria, \\ ${ }^{3}$ Institute of Health and Society, \\ Newcastle University, Newcastle upon \\ Tyne, UK
}

\begin{abstract}
Idiopathic Parkinson's disease (PD) is a progressive neurodegenerative disorder, secondary to dopaminergic depletion, which primarily affects motor control via the basal ganglia. It is a multi-system disease affecting dopaminergic neurons throughout the body. The Parkinsonian syndromes are associated with excess morbidity and mortality from respiratory causes. Pulmonary function studies have yielded conflicting results in PD. Understanding the pattern of any respiratory dysfunction in PD, and interventions that could modify these, is of importance in dyspnea, hypoxia, hypercapnia, pneumonia, speech, swallowing, sleep disordered breathing, daytime somnolence, acute respiratory failure, extubation difficulties, increased respiratory infections and reduced exercise tolerance and functional capacity. The aims of this review are to summarize the patterns of pulmonary dysfunction described in previous research in PD, describe the possible implications of pulmonary dysfunction on symptoms in PD, highlight considerations for physicians managing patients and suggest areas for future research.
\end{abstract}

Keywords: Parkinson's disease, pulmonary function, lung function, respiratory

\section{Introduction}

Pulmonary complications associated with idiopathic Parkinson's disease (PD) are a common reason for hospital admission. ${ }^{1,2}$ Lee et al evaluated symptom burden experienced by patients with PD with $35.8 \%$ reporting shortness of breath on exertion, $17.9 \%$ reporting cough and $13 \%$ reporting sputum production. ${ }^{3}$ A higher proportion of patients with PD die from pneumonia than in the general population. ${ }^{4}$ Previous research into the effect of PD on pulmonary function has produced varied and conflicting results. Obstructive and restrictive ventilatory defect patterns and upper airway and intercostal muscle problems have all been reported.

The respiratory or pulmonary system comprises the airways, lungs, muscles of respiration and the associated vasculature. Dysfunction of the respiratory system leads to increased morbidity and mortality and deterioration in quality of life. Signs and symptoms of respiratory dysfunction vary dependent on the part or parts of the pulmonary system involved.

Concomitantly with history and examination, measurement of respiratory function can be used to establish if any abnormality is present and identify particular disorders. Respiratory testing can be used to assess severity and prognosticate. Serial measurements are useful to assess response to treatment or progression of disease. Pulmonary function tests (PFTs) are a collection of non-invasive tests that measure airflow, lung volumes, gas exchange and respiratory muscle strength. Interpretation of tests should
Correspondence: Ailish O'Callaghan Department of Medicine, North Cumbria University Hospitals NHS Trust, Cumberland Infirmary, Newtown Road, Carlisle, Cumbria, CA2 7HY, UK Tel +44 I 228523444 (Extension 14029) Email ailish.o'callaghan@ncuh.nhs.uk 
always begin with a review of test quality. ${ }^{5}$ Interpretation of PFTs is based on comparisons of measured data with reference values based on healthy subjects.

\section{Impact of pulmonary dysfunction}

Potential signs and symptoms of pulmonary dysfunction are numerous, vary depending on the part or parts of the pulmonary system involved, and may include cough, difficulty coughing, dyspnea, pneumonia, aspiration, reduced exercise tolerance, speech difficulties, hypophonia, atelectasis, hypoxia, hypercapnia, sleep disordered breathing, excessive daytime somnolence, acute respiratory failure and difficulty in extubation. Iatrogenic causes of pulmonary dysfunction by medication may also be temporary or permanent.

Obstructive lung disease is characterized by lower airway obstruction and is caused by any disease that obstructs the airflow, for example, by narrowing the airways. Restrictive lung diseases are characterized by reduced lung volumes and have a variety of potential pulmonary and extrapulmonary causes. Extrapulmonary causes reduce volume and expansion. Speaking and swallowing require coordinated, precise upper airway movements; thus, upper airway obstruction (UAO) could contribute to speech and swallowing difficulties in addition to hypophonia, sleep disordered breathing, excessive daytime somnolence, acute respiratory failure and difficulty in extubation. Involvement of the upper airway musculature may be severe enough to limit airflow and demonstrate obstructive spirometry.

Respiratory muscle dysfunction is to be differentiated from lung function abnormalities. ${ }^{6}$ In generalized neuromuscular disorders, it is unusual for the respiratory muscles to be unaffected. ${ }^{7}$ Severe generalized respiratory muscle weakness manifests as breathlessness and tachypnea. When this weakness becomes sufficiently severe, nocturnal hypoventilation disturbs cognitive function and sleep resulting in daytime somnolence. ${ }^{7,8}$ The final sequelae are ventilatory failure and cor pulmonale. ${ }^{7}$ Inspiratory muscle weakness can contribute to hypoxia, tachypnea, increased respiratory infections, impaired functional capacity and can in part explain dyspnea and poor exercise tolerance. ${ }^{6}$ Expiratory muscle and bulbar weakness leads to speech problems and impairs cough and predisposes to mucus retention, pneumonia and aspiration. ${ }^{6,7}$ Poor respiratory muscle strength has been shown to be a predictive factor for mortality in both neuromuscular diseases, for example, amyotrophic lateral sclerosis (ALS), and non neuromuscular disorders such as congestive cardiac failure. ${ }^{9,10}$ Thus, patterns of dysfunction of the respiratory system lead to increased morbidity and mortality. Due to the disseminated nature of PD, with involvement of multiple body systems, and the identification of respiratory signs and symptoms in this population contributing to morbidity and mortality, it is vital in this group to understand how pulmonary complications occur and manifest. It is plausible that respiratory muscles may be involved in the pathophysiology of PD and involvement of upper airway musculature may be contributory to bulbar dysfunction and aspiration for example. Thus reviewing the evidence is vital to look at patterns of dysfunction and potential suggestions for management or further research.

\section{Review of pulmonary function in Parkinson's disease}

"He fetched his breath rather hard" was noted as a clinical feature by James Parkinson in his initial description of the disease in his 1817 essay An Essay on the Shaking Palsy. ${ }^{11}$ Despite this early recognition of respiratory involvement in PD, little remains known and debate continues about the pattern of ventilatory dysfunction associated with the disease. Obstructive patterns, restrictive patterns, UAO, respiratory muscle weakness and sleep breathing disorders have all been described but there is little consensus across the studies. Patterns of ventilatory dysfunction in previous research are summarized in Table 1.

The complexity and variety of the techniques used and outcome measures in each study warrant significant further discussion. With a range of results in each study, the review lends itself more to a chronological report than categorizing each study into one predominant pattern of pulmonary dysfunction as this may be misleading to the reader. Throughout the review, a variety of terminology is used by each author to describe the patient demographics. Some studies refer to Parkinson's disease (PD) or idiopathic Parkinson's disease (IPD), whereas others refer to Parkinsonism. The term Parkinsonism describes the clinical symptoms and signs seen in PD or IPD. These symptoms and signs can also be seen in other diseases such as vascular Parkinsonism, drug-induced Parkinsonism and Parkinson-plus syndromes. The group described as Parkinson-plus syndromes include multiple system atrophy (MSA), progressive supranuclear palsy, corticobasal degeneration and dementia with Lewy bodies. The Parkinson-plus syndromes demonstrate the signs and symptoms of PD but with distinct additional features that define each syndrome. Frequently mentioned throughout the review are rating scales, in particular Hoehn and Yahr. Hoehn and Yahr is a scale from 1 to 5 that describes the stages of PD, with 5 being the most severe.

Pulmonary function testing in patients with PD seemed to garner interest in the 1960s with a 1967 study by Neu et al, 
Table I Summary of the literature on pulmonary function in PD

\begin{tabular}{|c|c|c|c|c|c|c|}
\hline Study & $\begin{array}{l}\text { Number of } \\
\text { patients }\end{array}$ & $\begin{array}{l}\text { Pattern of } \\
\text { dysfunction }\end{array}$ & MIP/SNIP & MEP & UAO & $\begin{array}{l}\text { Effect of } \\
\text { dopaminergic } \\
\text { treatment }\end{array}$ \\
\hline \multirow[t]{2}{*}{ Neu et al'2 } & $23(10 \mathrm{M}, \mathrm{I3} \mathrm{F})$ & Obstructive & Reduced MIP & Reduced & & \\
\hline & Parkinsonism & & & & & \\
\hline Paulson and & 22 & & & & & $M V V$ increased \\
\hline Tafrate $^{13}$ & Parkinsonism & & & & & \\
\hline Obenour & $31(18 \mathrm{M}, 13 \mathrm{~F})$ & II obstructive & & & & Unchanged \\
\hline et $\mathrm{al}^{14}$ & PD & & & & & \\
\hline \multirow[t]{3}{*}{ Vincken et al ${ }^{15}$} & 27 (I9 M, 8 F) & & & & 24 abnormal flow volume & \\
\hline & Extrapyramidal & & & & loops & \\
\hline & disorders & & & & 10 UAO by author's criteria & \\
\hline Tzelepis et $\mathrm{al}^{16}$ & $9 \mathrm{PD}$ & Normal & Normal MIP & & & \\
\hline Hovestadt & $31(16 \mathrm{M}, \mathrm{I5} F)$ & Normal & Reduced & Reduced & $20-22$ abnormal flow volume & \\
\hline \multirow[t]{3}{*}{ et $\mathrm{al}^{17}$} & PD & & & & loops & \\
\hline & & & & & I8 had between I-3 UAO & \\
\hline & & & & & parameters & \\
\hline \multirow[t]{6}{*}{ de Bruin et al ${ }^{19}$} & $10(8 \mathrm{M}, 2 \mathrm{~F})$ & Normal & Reduced & Reduced & Off treatment & MEP and PIF increased \\
\hline & & & & & 8 abnormal curves & (significant) \\
\hline & & & & & PEF reduced & MIP and PEF \\
\hline & & & & & 2 fixed extrathoracic & increased \\
\hline & & & & & obstruction & (moderate) \\
\hline & & & & & I intrathoracic obstruction & $\begin{array}{l}\text { Maximal flow volume } \\
\text { curves improved }\end{array}$ \\
\hline Izquierdo- & 63 (39 M, 24 F) & $85 \%$ restrictive & & & $49.2 \%$ pathological curves & \\
\hline \multirow[t]{5}{*}{ Alonso et $\mathrm{a}^{20}$} & & & & & 21 type $A$ & \\
\hline & & & & & 9 type B & \\
\hline & & & & & I obstructive & \\
\hline & & & & & 3 patients had at least 2 & \\
\hline & & & & & spirometric indices of UAO & \\
\hline \multirow[t]{2}{*}{ Sabaté et $\mathrm{a}^{21}$} & $58(30 \mathrm{M}, 28 \mathrm{~F})$ & I8 obstructive & Reduced & Reduced & 36 UAO on 3 spirometric & \\
\hline & & 16 restrictive & & & indices & \\
\hline Köseoğlu & $9(4 \mathrm{M}, 5 \mathrm{~F})$ & I restrictive & & & 4 UAO on 2 spirometric & \\
\hline \multirow{3}{*}{ et $\mathrm{al}^{24}$} & & I obstructive & & & indices & \\
\hline & & & & & I type A curve & \\
\hline & & & & & 2 type $B$ curve & \\
\hline \multirow[t]{3}{*}{ Canning et $\mathrm{al}^{27}$} & $16(13 \mathrm{M}, 3 \mathrm{~F})$ & Normal & Normal & Normal & 16 curves with one or more & \\
\hline & & & & & abnormal features & \\
\hline & & & & & IO UAO by author's criteria & \\
\hline Vercueil et a ${ }^{28}$ & II (5 M, 6 F) & & & & & $\begin{array}{l}\text { Lengthening of } \\
\text { inspiratory duration }\end{array}$ \\
\hline \multirow[t]{5}{*}{ Polatli et $\mathrm{a}^{29}$} & $21(10 \mathrm{M}, \mathrm{II} F)$ & 3 of 6 ex-smokers & & & & \\
\hline & & obstructive & & & & \\
\hline & & 2 of 15 non- & & & & \\
\hline & & smokers & & & & \\
\hline & & obstructive & & & & \\
\hline \multirow[t]{2}{*}{ Herer et $\mathrm{a}^{30}$} & $21(14 \mathrm{M}, 7 \mathrm{~F})$ & & & & 5 patients had at least 4 & After levodopa \\
\hline & & & & & UAO criteria & $\begin{array}{l}2 \text { of the } 5 \text { met UAO } \\
\text { criteria }\end{array}$ \\
\hline De Pandis & 12 (5 M, 7 F) & Restrictive & & & & FEVI and FVC improved \\
\hline et $\mathrm{al}^{31}$ & & & & & & in the on state \\
\hline \multirow[t]{4}{*}{ Weiner et $\mathrm{al}^{32}$} & $20(10 \mathrm{M}, 10 \mathrm{~F})$ & Restrictive & Reduced & Reduced & & FEVI and FVC unchanged \\
\hline & & & & & & with treatment \\
\hline & & & & & & MIP and MEP increased \\
\hline & & & & & & $\begin{array}{l}\text { with treatment (not } \\
\text { significantly) }\end{array}$ \\
\hline
\end{tabular}


Table I (Continued)

\begin{tabular}{|c|c|c|c|c|c|c|}
\hline Study & $\begin{array}{l}\text { Number of } \\
\text { patients }\end{array}$ & $\begin{array}{l}\text { Pattern of } \\
\text { dysfunction }\end{array}$ & MIP/SNIP & MEP & UAO & $\begin{array}{l}\text { Effect of } \\
\text { dopaminergic } \\
\text { treatment }\end{array}$ \\
\hline $\begin{array}{l}\text { Cardoso and } \\
\text { Pereira }^{33}\end{array}$ & 40 (2I M, I9 F) & Restrictive & $\begin{array}{l}\text { Not reduced } \\
\text { compared to } \\
\text { control }\end{array}$ & $\begin{array}{l}\text { Not reduced } \\
\text { compared to } \\
\text { control }\end{array}$ & & \\
\hline Maria et $\mathrm{al}^{34}$ & 15 (I2 M, $3 \mathrm{~F})$ & Normal & Reduced & Reduced & & \\
\hline Haas et $\mathrm{al}^{35}$ & 66 (47 M, 19 F) & & Reduced & Reduced & & \\
\hline $\begin{array}{l}\text { Sathyaprabha } \\
\text { et } \mathrm{al}^{44}\end{array}$ & 35 & $\begin{array}{l}33 \text { restrictive } \\
2 \text { obstructive }\end{array}$ & Reduced & Reduced & & $\begin{array}{l}\text { FEVI, FVC, PEF, MIP, } \\
\text { MEP improved in the } \\
\text { on state }\end{array}$ \\
\hline Mikaelee et $\mathrm{al}^{45}$ & $25(19 M, 6 F)$ & I3 obstructive & & & $\begin{array}{l}\text { I UAO } \\
\text { on authors' criteria }\end{array}$ & \\
\hline $\begin{array}{l}\text { Silverman } \\
\text { et } \mathrm{al}^{46}\end{array}$ & 28 (I4 M, I4 F) & & $\begin{array}{l}30.8 \% \text { low } \\
69.2 \% \text { normal }\end{array}$ & $\begin{array}{l}71.4 \% \text { low } \\
28.6 \% \\
\text { normal }\end{array}$ & & \\
\hline Pal et $\mathrm{al}^{47}$ & $53(38 \mathrm{M}, \mathrm{I} 5 \mathrm{~F})$ & Restrictive & Reduced & Reduced & & $\begin{array}{l}\text { All PFT parameters } \\
\text { improved with levodopa }\end{array}$ \\
\hline Shaheen et $\mathrm{al}^{48}$ & $30(28 \mathrm{M}, 2 \mathrm{~F})$ & $\begin{array}{l}19 \text { restrictive } \\
5 \text { obstructive }\end{array}$ & & & & $\begin{array}{l}\text { Improved in the on } \\
\text { state (not significant) }\end{array}$ \\
\hline $\begin{array}{l}\text { Seccombe } \\
\text { et } \mathrm{al}^{49}\end{array}$ & 19 (I7 M, 2 F) & $\begin{array}{l}16 \text { normal } \\
2 \text { restrictive } \\
\text { I mild airflow } \\
\text { limitation }\end{array}$ & $13(68 \%)$ low & I 5 (79\%) low & Nil & \\
\hline Guedes et $\mathrm{al}^{50}$ & $26(16 \mathrm{M}, 10 \mathrm{~F})$ & & Reduced & Reduced & & $\begin{array}{l}\text { MIP and MEP not } \\
\text { significantly improved in } \\
\text { the on state }\end{array}$ \\
\hline Wang et $\mathrm{al}^{51}$ & $\begin{array}{l}30 \mathrm{PD} \\
(16 \mathrm{M}, \mathrm{I} 4 \mathrm{~F}) \\
27 \mathrm{MSA} \\
(14 \mathrm{M}, \mathrm{I} 3 \mathrm{~F})\end{array}$ & $\begin{array}{l}\text { I }(56.7 \%) \\
\text { restrictive } \\
\text { I }(3.3 \%) \text { central } \\
\text { obstructive } \\
\text { I3 }(43.3 \%) \\
\text { peripheric } \\
\text { obstructive }\end{array}$ & Reduced & Reduced & & \\
\hline
\end{tabular}

Abbreviations: F, female; FEVI, forced expiratory volume in one second; FVC, forced vital capacity; M, male; MIP, maximal inspiratory pressure; MEP, maximal expiratory pressure; MSA, multiple system atrophy; MVV, minute ventilatory volume; PD, Parkinson's disease; PEF, peak expiratory flow; PFT, pulmonary function test; PIF, peak inspiratory flow; SNIP, sniff nasal inspiratory pressure; UAO, upper airway obstruction.

comprising 23 patients with Parkinsonism. ${ }^{12}$ The patients had Parkinsonism rather than PD and no smoking history was documented. The measurement techniques, interpretation and reference values are different to those used currently. The authors concluded that the pattern was predominantly obstructive based on the airway resistance $\left(\mathrm{R}_{\mathrm{AW}}\right)$ being almost double the predicted values and more consistently present than any reduction in vital capacity (VC). They also commented on significant reductions in maximal inspiratory pressure (MIP), maximal expiratory pressure (MEP), maximum inspiratory flow (MIF) and maximum expiratory flow (MEF) and increasing dysfunction correlated with severity of disease. ${ }^{12} \mathrm{~A}$ basic 1970 study of 22 people with Parkinsonism demonstrated an improvement in minute ventilatory volume (MVV) following levodopa administration but VC was not significantly altered following levodopa. ${ }^{13}$ Little detail was given about the participants including pre-existing lung disease and smoking history. ${ }^{13}$
Obenour et al, performed spirometry and plethysmography on 31 PD patients and noted expiratory flow obstruction in $11 .{ }^{14}$ Increased residual volume (RV) and functional residual capacity were consistent with air trapping. $\mathrm{R}_{\mathrm{AW}}$ was higher in the obstructed group and lung recoil at total lung capacity (TLC) was lower in this group. The baseline lung function was assessed without levodopa therapy. After 6 weeks of levodopa therapy, all assessments were repeated with no improvement seen in pulmonary function. Smokers and individuals with obstructive lung disease were not excluded from the study and thus it is feasible that the expiratory flow obstruction was a result of co-existing lung disease. ${ }^{14}$

Previous studies reporting an obstructive defect, but with no agreement on cause or site, prompted a 1984 paper by Vincken et al interested in the involvement of upper airway musculature. ${ }^{15}$ Spirometry, lung volumes, single-breath 
nitrogen washout, MIP and MEP were performed in 27 people with extrapyramidal disorders (21 PD). UAO was considered present when an increased helium response was accompanied by 2 or more abnormal flow ratios (forced expiratory volume in one second [FEV1]/peak expiratory flow $[\mathrm{PEF}]>8.5 \mathrm{~mL} / \mathrm{L} / \mathrm{min}$ or $\mathrm{FEV} 1 / \mathrm{FEV} 0.5>1.5$ or maximum expiratory flow at $50 \% \mathrm{VC}[\mathrm{MEF} 50] /$ maximum inspiratory flow at $50 \%$ of VC [MIF50] $>1$ ) and a peak inspiratory flow $(\mathrm{PIF})<3 \mathrm{~L} / \mathrm{s}$. A helium response and either abnormal ratios or reduced PIF sufficed for a diagnosis of UAO if the flow volume loop also showed a UAO pattern. The patterns of UAO on the flow volume loops were categorized as either type A, respiratory flutter, with regular consecutive flow accelerations and decelerations, or type B, irregular abrupt changes in flow often dropping to zero. An abnormal flow volume loop pattern was seen in 24 (89\%), 18 type A and 6 type B patterns. By the author's criteria, 10 had UAO, with higher Hoehn and Yahr scores than those without UAO. ${ }^{15}$

Focused on respiratory muscle dysfunction, Tzelepis et al, undertook a 9 person study in mild to moderate PD compared to a control group. ${ }^{16}$ There was no evidence of obstructive or restrictive dysfunction and while the patients were able to perform single respiratory efforts well, demonstrating normal lung volumes and MIP, they had problems performing repetitive inspiratory resistive-loaded ventilatory efforts compared to controls. ${ }^{16}$

Prior studies had predominantly included patients with mild disease. Hovestadt et al and Bogaard et al studied pulmonary function in 31 people with more advanced disease, at least Hoehn and Yahr III. ${ }^{17,18}$ They excluded those with known lung disease or structural upper airway abnormality. All were on levodopa and anticholinergic drugs. Like the previous studies, there was heavy use of anticholinergic drugs in the management of PD. This is no longer the standard practice. They reported a trend for most parameters to decrease with increasing Hoehn and Yahr stage. Significant differences between the groups were only seen for the effort-dependent variables of PIF, PEF, MIP and MEP, with MIP, MEP, PEF and MEF50 significantly below normal values. Forced inspiratory volume in one second, VC and FEV1/VC were relatively normal. This study was reported in two different papers with some inconsistencies in reporting. ${ }^{17,18}$ Both papers reported that 4 patients had a type A flow volume curve; however, one paper reported that 16 had a type B curve, while the other reported that 18 had type B curve..$^{15,17,18}$ The authors considered PIF, FEV1/PEF and MEF50/MIF50 to be indicators of UAO and reported that 9 patients had an abnormal value for 1 parameter, 8 patients had an abnormal value for 2 parameters and 1 patient had all the 3 parameters. ${ }^{17}$
The effect of apomorphine on pulmonary function was considered in a 10 patient study by de Bruin et al. ${ }^{19}$ They assessed MIP, MEP, spirometry and maximal inspiratory and expiratory flow volume curves in people with PD (42-60 years) on and off apomorphine treatment. Treatment improved neurological scores; however, FVC off treatment was $84 \%$ predicted and did not change with treatment. Despite the relatively normal FEV1/FVC, only 2 of 10 patients had normal flow volume curves with the most common abnormality, both on and off treatment, being the increased volume expired before PEF was achieved and absence of the sharp peak and resultant rapid decline in maximum expiratory flow. Off apomorphine treatment MIP, MEP, PEF and PIF were all low. On treatment, significant improvements were seen in MEP and PIF and moderate improvements were seen in MIP and PEF. There was no exclusion if patients had pre-existing respiratory disease. ${ }^{19}$

In 1994, Izquierdo-Alonso et al conducted a 63 patient study with maximal inspiratory and expiratory flow volume curves. ${ }^{20}$ Spirometric findings were in contrast to those found in previous studies with 54 (85\%) having a FEV1/FVC ratio equal to or higher than $80 \%$ suggesting a restrictive element of pulmonary dysfunction. They also noted some weak but significant correlations between PD scales (Unified Parkinson's Disease Rating Scale [UPDRS] and Webster scales) and spirographic parameters, noting those with more severe disease had lower FVC\%, PIF and PEF and those with motor fluctuations and or dyskinesia had lower $\mathrm{FVC} \%$ and FEV1\%. Thirty one (49.2\%) patients had abnormal flow volume curves with 21 type A, 9 type B and 1 obstructive, and 3 patients had 2 or more spirometric indices (FEV1/PEF, FEV1/FEV0.5, forced expiratory flow at 50\% FVC [FEF50]/ forced inspiratory flow at 50\% RV [FIF50]) of UAO. Notably 29 patients were treated with pergolide, which is known to cause pleuropulmonary fibrosis that could show a restrictive pattern of spirometry. The authors used FEV1/FVC to define restriction rather than TLC. Use of TLC would give far superior accuracy to results. ${ }^{20}$

In 1996, Sabaté et al published a study of 58 patients that further complicated the picture. ${ }^{21,22}$ Sabate et al measured spirometry, lung volumes, $\mathrm{R}_{\mathrm{AW}}$ by body plethysmography, MIP and MEP in PD patients off dopaminergic medication for 8 hours prior to testing. Based on 3 spirometric indices $(\mathrm{PIF}<3 \mathrm{~L} / \mathrm{s}, \mathrm{FEV} 1 / \mathrm{PEF}>8.5 \mathrm{~L} / \mathrm{min}$ and MEF50/MIF50 >1), they reported that 36 patients had UAO. Central obstruction or peripheral obstruction was seen in 18 patients and restrictive dysfunction in 16 patients. Restrictive dysfunction was described as TLC $<85 \%$ or FEV1/FVC $>80 \%$ with FVC 
$<80 \%$; however, the authors failed to publish the number with TLC $<85 \%$. They noted that 16 patients had evidence of air trapping with RV $>120 \%$ and RV/TLC $>40 \%$ and 7 patients had a TLC $>120 \%$ suggesting lung insufflation. Maximal inspiratory and expiratory mouth pressures were reduced and whilst FVC, FEV1 and FEV1/FVC were all reported to be significantly below normal values, the group means for these spirometric indices were all above $81 \%$ of predicted. An increase in the passive $\mathrm{R}_{\mathrm{AW}}$ was found, bradykinesia was higher in those with UAO, rigidity was higher in those with obstruction and those with evidence of pulmonary dysfunction had evidence of impact on scores of activities of daily living. In summary, evidence was reported that PD patients have a reduction in MIP and MEP and a high incidence of restrictive and upper, central and peripheral obstructive patterns. $^{21,22}$

Pulmonary rehabilitation is a widely accepted and successful therapy for individuals with COPD with origins dating back to the middle of the 20 th century. ${ }^{23}$ With the knowledge that ventilatory and upper extremity exercise programs enhance maximal ventilatory capability and improve the effectiveness of ventilation during exercise, Koseoglu et al assessed 9 people with PD (versus 9 controls) pulmonary function and six-minute walk test (6MWT) before and after a 5 week exercise training program as part of a comprehensive pulmonary rehabilitation program. ${ }^{24-26}$ At baseline, a restrictive defect was seen in 1 patient, an obstructive defect in 1 patient (also smoked) and 4 had evidence of UAO as judged by 2 spirometric indices (PEF and FEF50/FIF50). Statistically significant differences were seen between the PD and control groups with regard to FVC, FEV1, FEF50, FEF25-75, MVV, PEF, PIF, IC, VC, FEF50/FIF50 and 6MWT, all being lower in the PD group. A slight increase was seen at follow-up in FVC, FEV1, FEF50, FEF25-75, PEF, PIF, VC, expiratory reserve volume, tidal volume and $\mathrm{MVV}$ and a slight reduction in IC and respiratory rate; however, these failed to reach statistical significance. A statistically significant increase was seen in minute ventilation and 6MWT. Two patients did not complete the study and there was high use of anticholinergic medications, which have systemic effects including on the respiratory system that can result in bronchodilation. ${ }^{24}$

Canning et al, sought to determine if abnormalities in respiratory function and gait affect exercise capacity. ${ }^{27}$ They performed spirometry, flow volume loops, lung volumes and mouth pressures in 16 people with PD, Hoehn and Yahr I-III. FEV1, FVC and FEV1/FVC were all normal and lung volumes did not indicate any obstructive or restrictive patterns. Mean MIP and MEP were not significantly different from predicted. PIF was significantly reduced and every flow volume loop had at least one abnormal characteristic of a rounded off PEF, low PIF, high MEF50/MIF50 >1 and tremor. Ten fulfilled criteria for UAO with FEV1/PEF $<8.5 \mathrm{~mL} / \mathrm{L} /$ min, MEF50/MIF50 $>1$ and a PIF $<80 \%$ of predicted normal value. While presence of UAO did not significantly correlate with percent predicted peak oxygen consumption achieved on maximal exercise testing, percent predicted PIF achieved did correlate with peak oxygen consumption. Noting the reduced flow rates, notably PIF, respiratory muscle weakness is often thought to contribute to these reduced flow rates; however, mouth pressures that were normal in this study provide only a global indication of respiratory muscle strength and may be altered by coordination of individual muscles. ${ }^{27}$

In 1999, identifying that little research looked at breathing patterns at rest in $\mathrm{PD}$, rather than forced maneuvers, Vercueil et al conducted an 11 patient study focused on breathing patterns at rest both in the off and on states (after levodopa). ${ }^{28}$ The amount of ventilatory changes induced by levodopa varied massively among the patients; however, the most prominent effect on the pattern of breathing seemed to be an increase in the inspiratory duration. All patients reported that levodopa alleviated any breathing discomfort. ${ }^{28}$

As recently as the last decade, pergolide with the potential to cause pulmonary fibrosis was still commonly used in the treatment of PD. In 2001 a study of pulmonary function in 21 PD patients was published by Polatli et al; however, 15 of the 21 patients included were on pergolide and 6 were also ex-smokers. ${ }^{29}$ Spirometry was performed in 21 PD patients (Hoehn and Yahr I-III) and 16 controls. Results showed 3 of 6 ex-smokers and 2 of 15 non-smokers had obstructive defects; however, they defined this as FEV1/VC $<89 \%$ predicted. They noted that FEV1 and MEF25 were unsurprisingly decreased in the ex-smokers; however, it was more noteworthy that MVV, PEF and MEF75 were significantly lower in the nonsmoker PD group than in the controls. There was a trend across the PFTs to deteriorate with advancing disease state, as defined by Hoehn and Yahr, with MVV best correlating with disease severity. ${ }^{29}$

With previous studies reporting a range in prevalence of UAO in PD and conflicting reports on the effect of dopaminergic medication on pulmonary function, Herer et al investigated the effects of levodopa on pulmonary function, specifically UAO. ${ }^{30}$ Spirometry and maximal inspiratory and expiratory flow volume curves were performed in 21 PD patients, Hoehn and Yahr II-IV, age 52-89 years, 12 hours after withdrawal from anti-Parkinsonian drugs, then repeated after administration of placebo or weight-dependent 
Co-beneldopa. The study was then repeated in all patients at 24 hours. The authors considered UAO to be present if at least 4 of the following 6 criteria were present: curve had a characteristic UAO saw-tooth sign, PIF $<3 \mathrm{~L} / \mathrm{s}, \mathrm{FEV} 1 /$ PEF $>8.5 \mathrm{~mL} / \mathrm{L} / \mathrm{min}$, FEV1/FEV0.5 >1.5, FEF50/FIF50 >1 and a PEF/FEF50 $<2$. At baseline, UAO was observed in 5 patients and after levodopa therapy 3 of these 5 no longer met the authors' criteria for UAO. Levodopa administration induced significant variations in PEF and the UAO ratios of FEV1/PEF and FEV1/FEV0.5. This study supported the hypothesis that levodopa improves lung function; however, the study was small, used levodopa doses that may have been insufficient in some patients and acknowledging that PEF measurements are subject to variability, the authors failed to specify reproducibility criteria. ${ }^{30}$

A brief publication in 2002 by De Pandis et al supported the finding of restrictive pulmonary function in advanced PD. ${ }^{31}$ They performed spirometry and arterial blood gases $(\mathrm{ABG})$ in the on and off states of 12 individuals with at least Hoehn and Yahr III. The spirometry results revealed a restrictive pattern in both the on and off states and $\mathrm{ABG}$ analysis revealed normal values for $\mathrm{PaO}_{2}, \mathrm{PaCO}_{2}$ and $\mathrm{pH}$ in both the on and off states but a significant increase in $\mathrm{PaCO}_{2}$ was seen in the off state. ${ }^{31}$ Of note TLC was not measured.

In 2002, Weiner et al reported spirometry, respiratory muscle strength and perception of dyspnea in the on and off state of 20 people with PD, with Hoehn and Yahr II-III, and compared their results to 20 controls. ${ }^{32}$ They reported that people with PD predominantly had spirometry data indicating a mild restrictive pattern and that the mean FEV1 and FVC were not significantly different in the on and off states. Similar to previous studies, the MIP and MEP in the off state were significantly reduced and although these values tended to improve in the on state, the results were not statistically significant. Perception of dyspnea was increased in the off state and improved in the on state. Close correlation was only seen between MIP and perception of dyspnea in the off state. ${ }^{32}$

In 2002, Cardoso and Pereira ${ }^{33}$ reported spirometry and respiratory muscle strength tests of $40 \mathrm{PD}$ patients, age 50-80 years, Hoehn and Yahr I-III, compared to 40 controls. A predominantly restrictive picture was reported noting a reduction in VC and FVC in the PD group; however, there was no difference in MIP and MEP between the PD and control groups. ${ }^{33}$ The breakdown for each Hoehn and Yahr group was not stated and TLC was not measured.

As part of a wider study into sleep breathing disorders in PD, Maria et al, reported basic spirometry, MIP and MEP in 15 people with PD and 15 controls. ${ }^{34}$ FEV1, FVC and FEV1/
FVC were normal in both groups; however, median values for MIP and MEP were significantly reduced in the PD group. ${ }^{34}$ The study did not exclude ex-smokers and predominantly included those with mild disease.

Whilst not publishing exact figures, Haas et al's 2004 study focused on respiratory muscle strength tests. ${ }^{35}$ Respiratory mouth pressures, activities of daily living, activity levels and quality of life questionnaires, peak heart rate, peak oxygen consumption, lactate thresholds and stages completed on a cycle ergometer test were recorded in 66 people with PD and 32 controls. Whilst MIP and MEP were found to be significantly lower in the PD group, this did not affect the results of the questionnaires but did correlate with lactate thresholds and ergometer stages completed. With an average Hoehn and Yahr of 2, this study supported a weakness of respiratory muscles in mild to moderate $\mathrm{PD}$, which seemed to affect individuals during exercise but not during tasks that required a smaller effort, for example, activities of daily living. ${ }^{35}$ The strength of skeletal muscles was not measured during this study. Previous studies have shown that whole body exercise training has the potential to improve respiratory muscles and improving inspiratory muscle strength has benefited other patient groups and athletes and can be safely done in patients with neuromuscular disorders. ${ }^{36-42}$

With interest in inspiratory muscle training Inzelberg et al measured respiratory muscle strength and endurance, perception of dyspnea and quality of life in 20 people with PD, Hoehn and Yahr II-III. ${ }^{43}$ The patients were then divided into 2 groups of 10 . One group received 12 weeks of $1 / 2$ hour, 6 times per week specific inspiratory muscle training and the other group received sham training. Significant improvements in inspiratory muscle strength, endurance and perception of dyspnea were seen only in the intervention group..$^{43}$

With lack of clarity on the effect of dopaminergic medication on pulmonary function, Sathyaprabha et al researched this further in a study published in 2005. ${ }^{44}$ Spirometry, respiratory muscle strength and MVV were performed in the off and on states (after levodopa therapy) on 35 people with PD and 35 controls. At baseline, they reported that the PD group had significantly lower FEV1, FVC, PEF, MVV, MIP and MEP compared to the controls and 33 of $35 \mathrm{PD}$ patients showed restrictive spirometry and 2 obstructive. Following administration of levodopa, all the aforementioned indices significantly improved. ${ }^{44}$ Lung volumes with TLC were again not measured in this study.

Using spirometry alone rather than including body plethysmography for assessment of lung volumes can lead to false positives of restrictive defects. In Iran, Mikaelee 
et al performed lung function testing including body plethysmographic measurements of lung volumes in 25 people with PD, Hoehn and Yahr I-V, mean age $63.8 \pm$ 11.1 years, compared to 20 controls. ${ }^{45}$ In the PD group, an obstructive pattern of respiratory dysfunction was found in $13(52 \%)$ and evidence of air trapping in $56 \%$ with a markedly raised RV. In contrast to previous studies, no evidence of restrictive spirometry was found and only 1 patient in the PD group had evidence of UAO (based on abnormal PIF and FEV1/PEF). Although there was a trend towards a correlation between increasing Hoehn and Yahr scores and abnormal pulmonary function, this was not statistically significant. ${ }^{45}$

An eminent American group in the field of speech and language therapy, including authors Silverman et al, published a study on mouth pressures in 2006 in 28 PD patients, mean age 64 years, Hoehn and Yahr II-III. ${ }^{46}$ MIP was less impaired than MEP when compared to controls, $69.2 \%$ of MIP measurements were within or above normal as opposed to only $28.6 \%$ of MEP measurements being within normal range. Whilst their MEP findings supported previous studies, their MIP findings contrasted. ${ }^{46}$

Members of the same group from the National Institute of Mental Health and Neurosciences in Bangalore who published a 35 patient study in 2005 reported a further study in 53 patients in $2007 .{ }^{47} \mathrm{Pal}$ et al assessed spirometry, MIP and MEP in the off state and the on state (after levodopa administration) in people with PD, Hoehn and Yahr II-IV (predominantly stage II) with a mean duration of PD of 3.1 years, as compared to 53 controls. However, they did not publish if these participants included those from the previous study. Nineteen patients in the PD group and 5 controls were smokers, with all smokers being male. Whilst spirometry was measured with standardized commercially available equipment, the pressure monitor used to measure MIP and MEP was fabricated. They concluded that the pattern of pulmonary dysfunction in the PD group was restrictive; however, they did not publish exact numbers and they noted a significant impairment in FEV1, FVC, PEF, MVV, MEP and MIP in both the off and on state in the PD group compared to the controls. All PFT parameters improved with levodopa but remained worse than the control group. They recorded the percent predicted values of FVC, FEV1, MVV, MIP and MEP to be significantly lower in women than in men in the PD group only. Although there were several correlations between PFT parameters and UPDRS motor subscores, these did not reach statistical significance. ${ }^{47}$
A further 2 years passed without any significant publications pertaining to pulmonary function in PD. In 2009, Shaheen et al published a basic spirometry study of 30 patients with PD, mean age 67.7 years, mean disease duration 3 years, with $77 \%$ tremor dominant disease and $23 \%$ presenting mainly with akinesia. ${ }^{48}$ PFTs comprised FEV1 and FVC in the off and on states (after levodopa) compared to 15 controls. They concluded, similar to Pal et al, that the pattern of dysfunction was predominantly restrictive, with a restrictive defect observed in 19 (63.3\%) and an obstructive defect observed in $5(16.7 \%)$ PD patients. Thus, $80 \%$ had abnormal spirometry and whilst they noted pulmonary function parameters improved with levodopa treatment, the improvement did not reach statistical significance. ${ }^{48}$

Identifying that respiratory involvement in PD could potentially occur through more than one mechanism, i.e., peripheral or central, Seccombe et al conducted a 19 patient study, published in 2011, to identify further evidence of abnormal ventilatory control in PD. ${ }^{49}$ Predominantly, lung function studies have looked at peripheral motor manifestations such as tremor or rigidity affecting lung function rather than the effect brain stem involvement has on respiratory control. Seccombe et al measured spirometry, lung volumes (body plethysmography), respiratory muscle strength, response to hypoxic gas inhalation and hypercapnic ventilatory response and occlusion pressure in 19 people with PD in the on state. Normal lung function was observed in 16 patients, mild airflow limitation was observed in 1 patient and 2 patients demonstrated restrictive dysfunction based on TLC. No flow volume loops were consistent with UAO. MIP and MEP were reduced in $68 \%$ and $78 \%$ of patients, respectively. Four patients were unable to maintain an adequate seal to complete the hypercapnic ventilatory response (which was abnormal in 47\%) and occlusion pressure (which was abnormal in $73 \%$ ). Most subjects had normal ABGs before and following the altitude simulation test. The authors demonstrated impaired respiratory drive in response to hypercapnia, and the abnormal occlusion pressure response indicated central drive impairment; however, it has to be remembered that respiratory muscle myopathy may have an inhibitory effect on this central measure and it is possible that reduced respiratory muscle strength contributed in some way to the abnormal response observed. ${ }^{49}$

In 2012, Guedes et al published a limited study focused on MIP and MEP in 26 people with PD, age 50-75 years, Hoehn and Yahr II-III, compared to 26 controls. ${ }^{50}$ The PD group had measurements in the on and off states. In support of previous studies, MIP and MEP in PD in both the on and 
off states were lower than the control group. This failed to reach significance in the female PD MIP results. In contrast to previous studies, with the exception of PD female MEP results, any change in respiratory muscle strength in the on and off states failed to reach statistical significance. ${ }^{50}$

Finally, identifying the limited pulmonary function comparative data in PD and healthy subjects, and even more limited data between different Parkinsonian disorders, Wang et al compared spirometry, lung volumes (body plethysmography), DLCO, MIP and MEP in people with PD, people with MSA and healthy subjects. They tested 30 people with PD (mean age 61.8 years, mean disease duration 4.9 years), 27 people with MSA (mean age 59.85 years, mean disease duration 3.63 years) and 20 controls (mean age 60.85 years). ${ }^{51}$ Hoehn and Yahr stage was II-V for the PD group and the MSA group comprised 20 probable and 7 possible MSA. Spirometry showed a restrictive pattern in $56.7 \%$ of $\mathrm{PD}$ patients (63\% MSA), central obstructive in 3.3\% PD $(0 \%$ MSA) and peripheric obstructive pattern in $43.3 \%$ of PD (29.6\% MSA). Compared to controls, both PD and MSA groups had lower VC and higher RV, while there were no significant differences in TLC between the groups. In both the PD and MSA groups, VC, FEV1 and FVC decreased and MIP and MEP decreased markedly. Interestingly, diffusing capacity of the lung for carbon monoxide (DLCO) was only notably reduced in the MSA group. In PD patients, VC, FVC, FEV1, PEF, MIP and MEP all negatively correlated with UPDRS-III motor section, concluding the more seriously the patient is affected by motor symptoms, rather than disease duration, the greater the negative influence on pulmonary function. ${ }^{51}$ When reviewing this study, the authors based the conclusion of restrictive dysfunction in this Chinese PD population on the results of spirometric tests and not TLC. From the graphical representation of TLC, it would appear that the mean percentage predicted TLC was above $80 \%$ in all groups, which would indicate an alternative conclusion.

\section{Management and conclusion}

This comprehensive literature review of pulmonary function in PD highlights the small number of studies, with small numbers of participants and the disparity in results and conclusions. Aside from the numbers involved, the reviewed studies have a number of factors that must be taken into account: varying age groups, different Hoehn and Yahr stages and varying definitions of PD. The selection of anti-Parkinsonian medication used across the studies is vast, including a number of drug groups, or individual drugs, that are no longer commonly used predominantly due to their side effects. The studies reviewed did not consistently use equipment standardized in the same way and used different definitions in pulmonary function testing. Presumably due to availability, the majority lacked measurement of lung volumes by body plethysmography resulting in patterns of dysfunction being determined by spirometry alone, which can lead to interpretive errors particularly in restrictive dysfunction.

What is evident from this review is the presence of abnormal pulmonary function associated with PD, although debate continues as to the predominant pattern.

These findings highlight the need for significant further research using gold standard techniques to assess pulmonary function in PD and the Parkinsonian syndromes and to assess the benefit of rehabilitation of the pulmonary system, both pharmacologically and non-pharmacologically.

Advice on management of pulmonary complications in $\mathrm{PD}$ is difficult due to the varying and conflicting results of previous studies and those with small numbers. The potential impact of pulmonary dysfunction in PD, as highlighted earlier, and the prevalence of abnormal pulmonary function results should prompt clinicians to consider further investigation in some patients. Clinicians should consider pulmonary function assessments particularly in those with signs or symptoms of aspiration, sleep disordered breathing, excessive daytime somnolence (if other causes excluded), episodes of acute respiratory failure and in those with hypoxia and or hypercapnia in the absence of other causes. Further research is needed to clarify patterns of pulmonary dysfunction and the most appropriate management. The effect of different dopaminergic treatments on pulmonary function needs to be assessed in detail, and non-pharmacological treatment options warrant further research. Non-pharmacological options may include pulmonary rehabilitation style programs, specific expiratory muscle training, specific inspiratory muscle training and evaluation of different generalized whole body exercise regimes including aerobic, resistance, mixed and high-intensity interval training. Given the associated morbidity and mortality, this is an interesting area warranting further research.

\section{Disclosure}

The authors report no conflicts of interest in this work.

\section{References}

1. Woodford H, Walker R. Emergency hospital admissions in idiopathic Parkinson's disease. Mov Disord. 2005;20(9):1104-1108.

2. Tan LC, Tan AK, Tjia HT. The profile of hospitalised patients with Parkinson's disease. Ann Acad Med Singapore. 1998;27(6):808-812.

3. Lee MA, Prentice WM, Hildreth AJ, Walker RW. Measuring symptom load in idiopathic Parkinson's disease. Parkinsonism Relat Disord. 2007;13(5):284-289. 
4. Pennington S, Snell K, Lee M, Walker R. The cause of death in idiopathic Parkinson's disease. Parkinsonism Relat Disord. 2010;16(7):434-437.

5. Pellegrino R, Viegi G, Brusasco V, et al. Interpretative strategies for lung function tests. Eur Respir J. 2005;26(5):948-968.

6. Troosters T, Gosselink R, Decramer M. Respiratory muscle assessment. Eur Respir Mon. 2005;31:57-71.

7. Polkey MI, Green M, Moxham J. Measurement of respiratory muscle strength. Thorax. 1995;50(11):1131-1135.

8. Smith PE, Calverley PM, Edwards RH. Hypoxemia during sleep in Duchenne muscular dystrophy. Am Rev Respir Dis. 1988;137(4):884-888.

9. Polkey MI, Lyall RA, Yang K, Johnson E, Leigh PN, Moxham J. Respiratory muscle strength as predictive biomarker for survival in amyotrophic lateral sclerosis. Am J Respir Crit Care Med. 2017;195(1):86-95.

10. Meyer FJ, Borst MM, Zugck C, et al. Respiratory muscle dysfunction in congestive heart failure: clinical correlation and prognostic significance. Circulation. 2001;103(17):2153-2158.

11. Parkinson J. An Essay on the Shaking Palsy. London: Sherwood, Neely and Jones; 1817.

12. Neu HC, Connolly JJ Jr, Schwertley FW, Ladwig HA, Brody AW. Obstructive respiratory dysfunction in parkinsonian patients. Am Rev Respir Dis. 1967;95(1):33-47.

13. Paulson GD, Tafrate RH. Some "minor" aspects of parkinsonism, especially pulmonary function. Neurology. 1970;20(12):14-17.

14. Obenour WH, Stevens PM, Cohen AA, McCutchen JJ. The causes of abnormal pulmonary function in Parkinson's disease. Am Rev Respir Dis. 1972;105(3):382-387.

15. Vincken WG, Gauthier SG, Dollfuss RE, Hanson RE, Darauay CM, Cosio MG. Involvement of upper-airway muscles in extrapyramidal disorders. A cause of airflow limitation. $N$ Engl J Med. 1984;311(7):438-442.

16. Tzelepis GE, McCool FD, Friedman JH, Hoppin FG Jr. Respiratory muscle dysfunction in Parkinson's disease. Am Rev Respir Dis. 1988;138(2):266-271.

17. Hovestadt A, Bogaard JM, Meerwaldt JD, van der Meche FG, Stigt J. Pulmonary function in Parkinson's disease. J Neurol Neurosurg Psychiatry. 1989;52(3):329-333.

18. Bogaard JM, Hovestadt A, Meerwaldt J, vd Meche FG, Stigt J. Maximal expiratory and inspiratory flow-volume curves in Parkinson's disease. Am Rev Respir Dis. 1989;139(3):610-614.

19. de Bruin PF, de Bruin VM, Lees AJ, Pride NB. Effects of treatment on airway dynamics and respiratory muscle strength in Parkinson's disease. Am Rev Respir Dis. 1993;148(6 Pt 1):1576-1580.

20. Izquierdo-Alonso JL, Jiménez-Jiménez FJ, Cabrera-Valdivia F, Mansilla-Lesmes M. Airway dysfunction in patients with Parkinson's disease. Lung. 1994;172(1):47-55.

21. Sabaté M, González I, Ruperez F, Rodriguez M. Obstructive and restrictive pulmonary dysfunctions in Parkinson's disease. J Neurol Sci. 1996;138(1-2):114-119.

22. Sabaté M, Rodríguez M, Méndez E, Enríquez E, González I. Obstructive and restrictive pulmonary dysfunction increases disability in Parkinson disease. Arch Phys Med Rehabil. 1996;77(1):29-34.

23. Casaburi R. A brief history of pulmonary rehabilitation. Respir Care. 2008;53(9):1185-1189.

24. Köseoğlu F, Inan L, Ozel S, et al. The effects of a pulmonary rehabilitation program on pulmonary function tests and exercise tolerance in patients with Parkinson's disease. Funct Neurol. 1997;12(6):319-325.

25. Ries AL. The importance of exercise in pulmonary rehabilitation. Clin Chest Med. 1994;15(2):327-337.

26. Celli BR. The clinical use of upper extremity exercise. Clin Chest Med. 1994;15(2):339-349.

27. Canning CG, Alison JA, Allen NE, Groeller H. Parkinson's disease: an investigation of exercise capacity, respiratory function, and gait. Arch Phys Med Rehabil. 1997;78(2):199-207.

28. Vercueil L, Linard JP, Wuyam B, Pollak P, Benchetrit G. Breathing pattern in patients with Parkinson's disease. Respir Physiol. 1999;118(2-3):163-172.

29. Polatli M, Akyol A, Cildag O, Bayulkem K. Pulmonary function tests in Parkinson's disease. Eur J Neurol. 2001;8(4):341-345.
30. Herer B, Arnulf I, Housset B. Effects of levodopa on pulmonary function in Parkinson's disease. Chest. 2001;119(2):387-393.

31. De Pandis MF, Starace A, Stefanelli F, et al. Modification of respiratory function parameters in patients with severe Parkinson's disease. Neurol Sci. 2002;23 (Suppl 2):S69-S70.

32. Weiner P, Inzelberg R, Davidovich A, et al. Respiratory muscle performance and the perception of dyspnea in Parkinson's disease. Can J Neurol Sci. 2002;29(1):68-72.

33. Cardoso SR, Pereira JS. ANÁLISE DA FUNÇÃO RESPIRATÓRIA NA DOENÇA DE PARKINSON. [Analysis of breathing function in Parkinson's disease]. Arq Neuropsiquiatr. 2002;60(1):91-95. Portuguese

34. Maria B, Sophia S, Michalis M, et al. Sleep breathing disorders in patients with idiopathic Parkinson's disease. Respir Med. 2003;97(10): 1151-1157.

35. Haas BM, Trew M, Castle PC. Effects of respiratory muscle weakness on daily living function, quality of life, activity levels, and exercise capacity in mild to moderate Parkinson's disease. Am J Phys Med Rehabil. 2004;83(8):601-607.

36. Enright S, Chatham K, Baldwin J, Griffiths H. The effect of fixed load incremental inspiratory muscle training in the elite athlete: a pilot study. Phys Ther Sport. 2000;1(1):1-5.

37. Rutchik A, Weissman AR, Almenoff PL, Spungen AM, Bauman WA, Grimm DR. Resistive inspiratory muscle training in subjects with chronic cervical spinal cord injury. Arch Phys Med Rehabil. 1998;79(3):293-297.

38. Sánchez Riera H, Montemayor Rubio T, Ortega Ruiz F, et al. Inspiratory muscle training in patients with COPD: effect on dyspnea, exercise performance, and quality of life. Chest. 2001;120(3):748-756.

39. Cahalin LP, Semigran MJ, Dec GW. Inspiratory muscle training in patients with chronic heart failure awaiting cardiac transplantation: results of a pilot clinical trial. Phys Ther. 1997;77(8):830-838.

40. McCool FD, Tzelepis GE. Inspiratory muscle training in the patient with neuromuscular disease. Phys Ther. 1995;75(11):1006-1014.

41. Koessler W, Wanke T, Winkler G, et al. 2 Years' experience with inspiratory muscle training in patients with neuromuscular disorders. Chest. 2001;120(3):765-769.

42. Powers SK, Criswell D. Adaptive strategies of respiratory muscles in response to endurance exercise. Med Sci Sports Exerc. 1996;28(9):1115-1122.

43. Inzelberg R, Peleg N, Nisipeanu P, Magadle R, Carasso RL, Weiner P. Inspiratory muscle training and the perception of dyspnea in Parkinson's disease. Can J Neurol Sci. 2005;32(2):213-217.

44. Sathyaprabha TN, Kapavarapu PK, Pall PK, Thennarasu K, Raju TR. Pulmonary functions in Parkinson's disease. Indian J Chest Dis Allied Sci. 2005;47(4):251-257.

45. Mikaelee H, Yazdchi M, Ansarin K, Arami MA. Pulmonary function test abnormalities in Parkinson disease. Internet J Pulm Med. 2007;8(2):1.

46. Silverman EP, Sapienza CM, Saleem A, et al. Tutorial on maximum inspiratory and expiratory mouth pressures in individuals with idiopathic Parkinson disease (IPD) and the preliminary results of an expiratory muscle strength training program. NeuroRehabilitation. 2006;21(1):71-79.

47. Pal PK, Sathyaprabha TN, Tuhina P, Thennarasu K. Pattern of subclinical pulmonary dysfunctions in Parkinson's disease and the effect of levodopa. Mov Disord. 2007;22(3):420-424.

48. Shaheen HA, Ali MA, Abd Elzaher MA. Parkinson's disease and pulmonary dysfunction. Egypt J Neurol Psychiat Neurosurg. 2009;46(1): 129-140.

49. Seccombe LM, Giddings HL, Rogers PG, et al. Abnormal ventilatory control in Parkinson's disease - further evidence for non-motor dysfunction. Respir Physiol Neurobiol. 2011;179(2-3):300-304.

50. Guedes LU, Rodrigues JM, Fernandes AA, Cardoso FE, Parreira VF. Respiratory changes in Parkinson's disease may be unrelated to dopaminergic dysfunction. Arq Neuropsiquiatr. 2012;70(11):847-851.

51. Wang Y, Shao WB, Gao L, et al. Abnormal pulmonary function and respiratory muscle strength findings in Chinese patients with Parkinson's disease and multiple system atrophy — comparison with normal elderly. PLoS One. 2014;9(12):e116123. 
Journal of Parkinsonism and Restless Legs Syndrome is an online, open access, peer-reviewed journal. The journal publishes review articles, historical reviews, original research articles, case reports, letters to the editor, clinical teaching cases, neuroradiology highlights, neuropathology highlights, neuropsychiatry highlights, autobiographies, conference proceedings, abstracts and book reviews. The manuscript management system is completely online and includes a very quick and fair peerreview system, which is all easy to use. Visit http://www.dovepress.com/ testimonials.php to read real quotes from published authors.

Submit your manuscript here: https://www.dovepress.com/journal-of-parkinsonism-and-restless-legs-syndrome-journal 